Original Research Paper

\title{
Cryptococcosis Neuro-Brain in 42 Patients at the University Hospital of Brazzaville
}

\author{
Ossibi Ibara Bienvenu Rolland, Mabiala Babela Jean Robert, \\ Attinsounon Cossi Angelo, Atipo Ibara Ollandzobo Lucie, Sekangue Obili Geril, Gouesse Grace, \\ Angonga Pabota Ella, Boumandouki Pau Jean Claude, Puruhence Marie Francke and Obengui \\ Infectious Disease Unit, Brazzaville CHU, BP: 1846 Brazzaville, Congo
}

Corresponding Author: Ossibi Ibara Bienven Rolland Infectious Disease Unit, Brazzaville CHU, BP: 1846 Brazzaville, Congo Tel: 002420697936 94/ 055224226

E-mail: bienvenu_07@yahoo.fr

\begin{abstract}
To describe epidemiological, clinical, therapeutic; and evolutionary aspects of Neuromeningeal Cryptococcus (NMC) at Brazzaville University Hospital and to find out factors associated to death. A descriptive and analytical retrospective study of NMC files in the infectious diseases department between January 1 and December 31, 2013. 973 patients were hospitalized, 42 NMC cases (4.3\%) were compiled. The mean age was $40.2 \pm 10.4$ years (17-64 years). The sex ratio $\mathrm{M} / \mathrm{F}$ was 1.1 . The majority $(\mathrm{n}=23)$ came from an urban area. HIV infection $(n=37-88.1 \%)$ was the main point with an average of lymphocyte LTCD4 with $101.3 \pm 123.58 / \mathrm{mm}^{3}$. The average patient consultation time was $27.5 \pm 33.6$. Fever $(\mathrm{n}=36,85.7 \%)$, headache $(\mathrm{n}=11$, $26.2 \%)$ and consciousness disorders $(n=13,31.0 \%)$ were the primary reasons for consultation. LCR was clear in 32 patients and neuromeningeal Cryptococcus was confirmed by CSF in all patients $(\mathrm{n}=42,100 \%)$. Treatment was fluconazole $(800-2000 \mathrm{mg})$ in all patients. No adverse effects related to fluconazole were noticed. Six patients underwent lumbar puncture discharge and 23 patients (54.8\%) were on antiretroviral therapy. The lethality was $74.0 \% \quad(\mathrm{n}=31)$, with no significant difference depending on the stage of immunosuppression and etiologic treatment. It was significantly higher in comatose patients with Glasgow $\leq 8$. Neuromeningeal Cryptococcus is a frequent opportunistic infection in our service with high lethality. This shows how important is the prevention which implies the early management of HIV infection.
\end{abstract}

Keywords: Neuromeningeal Cryptococcus, HIV Infection, Coma, CHUBrazzaville

\section{Introduction}

Cryptococcosis or torulosis is a deep mycosis which is caused by an encapsulated fungus, Cryptococcus neoformans, which is found in house dust, bat guanos or pigeon droppings (Dromer et al., 2004). Transmitted mainly via the respiratory route, this affection mostly affects immunocompromised individuals who are mainly infected with HIV but also suffering from other immunological disorders or receiving immunosuppressive treatments. It very often leads to meningoencephalitis, the main localization of this affection; the primary infection being pulmonary (Aberg et al., 1999).

Neuromeningeal Cryptococcosis is a public health problem in developing countries because of high frequency and high mortality (Dromer et al., 2004). It represents the first cause of lymphocytic meningitis in adult-young with weakened immune system by HIV (Aberg et al., 1999). In Africa and certainly in Congo, it is the second most fatal opportunistic infection after tuberculosis, affecting most patients with weakened immune system not benefiting from time of a highly active triple antiretroviral therapy (Aberg et al., 1999). Cryptococcal meningitis has a highly variable prevalence, ranging from 3\% in Côte d'Ivoire to $15 \%$ in Central and Eastern Africa. This infection is also common in Southeast Asia. Cryptococcosis is an infection associated with high mortality whose clinical diagnosis is difficult because of the frequency of nonspecific tables (fever and/or persistent headache 
without meningeal syndrome). Conversely, the biological diagnosis is easy thanks to the detection of Cryptococcus spores by a Chinese ink test on the cerebrospinal fluid, which can, however, present neither hypercytose nor hyperproteinorachie. Thus, the lumbar puncture must be made in the least suspicion (Eholié et al., 2000).

To our knowledge, no study has been devoted to this condition in the Infectious Diseases Department at the Brazzaville University Hospital. This study aimed to describe epidemiological, clinical and progressive aspects of CNM and to identify factors connected with death.

\section{Patients and Method}

This study was descriptive and analytical retrospective based on the use of hospital and medical records of patients admitted to the Infectious Diseases for Neuromeningic Cryptococcal Disease department and the hospital's Parasitology and Mycology Laboratory in Brazzaville between January 1 and December 31, 2013. Patients implied in this study were at least 16 years old, with NMC confirmed by CSF analysis after direct examination with Indian ink and hospitalized during the study period and treated with fluconazole. The NMC diagnosis was based on epidemiological reasons (field of immunosuppression, proximity to favoring factors, clinical factors (fever, headache, vomiting and/or constipation, meningeal and immunosuppression signs) and the presence of Cryptococci in the cerebrospinal fluid spinal cord after staining with Indian ink, the only test available in our hospital for the diagnosis of this condition. The analysis of each patient file was carried out according to age, sex, profession, place of residence, the consultation reason, the consultation time, serological status for HIV, disease status based on the WHO classification, cyto-biochemical and mycological CSF results, CD4 lymphocyte rates, cerebral neuroimagery evolutionary aspects (healing, sequelae, death). The diagnosis of HIV / AIDS infection was done from clinical and serologic tests. All patients were treated with fluconazole. The rules of ethics, as well as the free consent for the use of the data obtained, were respected.
A descriptive study on epidemiological, clinical and evolutionary aspects was carried out. The results were expressed in terms of a percentage for the qualitative variables and on average and standard deviation for the quantitative variables. The factors associated with the occurrence of death were estimated using Odds Ratio (OR) and their 95\% Confidence Interval (CI). The influence of each variable on the occurrence of death was tabulated by the Pearson chi-square test with a significance level of $5 \%$.

\section{Results}

During the study period, 973 patients were admitted to the infectious diseases department. Based on the inclusion criteria, 42 patients were selected for our study, hence representing $4.3 \%$ of the passages in the service. The sex ratio $\mathrm{H} / \mathrm{F}$ was 1.3 . These subjects were around $40.2 \pm 10.4$ years (range: 17 to 64 years). The majority of patients lived in the city $(54.8 \%)$. Five patients $(5.9 \%)$ had negative retroviral serology at admission

The average patient consultation time was $27.5 \pm 33.6$. Fever $(\mathrm{n}=36,85.7 \%)$, headache $(\mathrm{n}=11,26.2 \%)$ and consciousness disorders $(n=13,31.0 \%)$ were the primary reasons for consultation. Table $1 \mathrm{CSF}$ was clear for all patients $(100 \%)$. The number of cells ranged from 1 to 413 elements per cubic millimeter, $100 \%$ lymphocytes. The mean value of albuminorrachia was $0.50 \mathrm{~g} / 1$ and Cryptococci was identified after CSF staining with Chinese ink in all patients $(n=42,100 \%)$. The mean delay in confirming the diagnosis was 5 days (Aberg et al., 1999; Aoufi et al., 2008; Eholié et al., 2000; Aoussi et al., 2012; Sow et al., 1998; Millogo et al., 2004; Kivukuto et al., 2012; Gbangba-Ngai et al., 2014; Soumare et al., 2005). There were thirty-seven weakened immune system patients with HIV1 (88.1\%). The mean number of LTCD4 was $101.3 \pm 123.58 / \mathrm{mm}^{3}$ (range: $50-421 / \mathrm{mm}^{3}$ ). All patients were treated with fluconazole. Tolerance was good in all cases. Six patients $(14.3 \%)$ benefited from a lumbar puncture and 23 patients $(54.8 \%)$ were on antiretroviral therapy. Thirty one patients (74\%) died. Lethality was significantly higher in comatose patients with Glasgow $\leq 8$ (Table 2).

Table 1: Patient distribution in terms of clinical manifestations

\begin{tabular}{lcc}
\hline Clinical manifestations & $\mathrm{n}$ & $\%$ \\
\hline Fever & 36 & 85,7 \\
Conscious trouble & 13 & 31,0 \\
Headache & 11 & 26,0 \\
Vomiting & 5 & 11,9 \\
Cranial nerve attack & 5 & 11,9 \\
Psychic Agitation & 4 & 9,5 \\
Convulsive crisis & 4 & 9,5 \\
\hline
\end{tabular}


Table 2: Factors related to death

\begin{tabular}{|c|c|c|c|c|c|}
\hline Parameters & & Recovery n (\%) & Death n $(\%)$ & $\mathrm{N}(\%)$ & P-value \\
\hline \multicolumn{6}{|l|}{$\overline{\text { Sex }}$} \\
\hline & Male & $7(28)$ & $18(72)$ & $25(100)$ & \multirow[t]{2}{*}{0.51000} \\
\hline & Female & $4(23,53)$ & $13(76,47)$ & $17(100)$ & \\
\hline \multicolumn{6}{|c|}{ Age group (years) } \\
\hline & $20-29$ & $1(33,33)$ & $2(66,67)$ & $3(100)$ & 0.60000 \\
\hline & $30-39$ & $3(23,08)$ & $10(76,92)$ & $13(100)$ & 0.50000 \\
\hline & $40-49$ & $5(25)$ & $15(75)$ & $20(100)$ & 0.20000 \\
\hline & $50-65$ & $2(33,33)$ & $4(66,67)$ & $6(100)$ & 0.50000 \\
\hline \multicolumn{6}{|c|}{ HIV serology } \\
\hline & Positive & $10(27,03)$ & $27(72,97)$ & $37(100)$ & \multirow[t]{2}{*}{0.60000} \\
\hline & Negative & $1(20)$ & $4(80)$ & $5(100)$ & \\
\hline \multicolumn{6}{|l|}{ Tritherapy } \\
\hline & Yes & $6(26,09)$ & $17(73,91)$ & $23(100)$ & \multirow[t]{2}{*}{0.17000} \\
\hline & No & $5(26,32)$ & $14(73,68)$ & $19(100)$ & \\
\hline \multicolumn{6}{|c|}{ LCR Cytology } \\
\hline & $<10$ & $5(19,23)$ & $21(80,77)$ & $26(100)$ & \multirow[t]{2}{*}{0.34000} \\
\hline & $\geq 10$ & $6(37,5)$ & $10(62,5)$ & $16(100)$ & \\
\hline \multicolumn{6}{|l|}{ Glasgow } \\
\hline & $<8$ & $0(0.0)$ & $18(100)$ & $18(100)$ & \multirow[t]{2}{*}{0.00083} \\
\hline & $\geq 8$ & $11(45,83)$ & $13(54,17)$ & $24(100)$ & \\
\hline \multicolumn{6}{|c|}{ Consultation time } \\
\hline & $<48 \mathrm{~h}$ & $8(25)$ & $24(75)$ & $32(100)$ & \multirow[t]{2}{*}{0.50000} \\
\hline & $\geq 48 \mathrm{~h}$ & $3(30)$ & $7(70)$ & $10(100)$ & \\
\hline
\end{tabular}

\section{Discussion}

The NMC prevalence is high in our study as attested in Abidjan, Dakar, Burkina Faso and Kivu. (Aoufi et al., 2008; Eholié et al., 2000; Aoussi et al., 2012; Sow et al., 1998). However, it is low in Bangui (Millogo et al., 2004). These differences can be partly explained by methodological and socio-cultural peculiarities of the populations covered by this study. Young people are the most affected, mostly male, living in the city. It is a sexually active population as shown in the literature (Kivukuto et al., 2012). The difference in sex suggests that genetic and hormonal factors are very important under this condition (Kivukuto et al., 2012) (Eholié et al., 2000; Kivukuto et al., 2012). Cryptococcosis factors such as house dust, pigeon droppings and bat guanos are most prevalent in the city. Neuromeningeal cryptococcosis occurs very commonly in HIV-infected and profoundly immunosuppressed patients so that it constitutes the second opportunistic infection once there is AIDS (Aberg et al., 1999). In the United States, more than 80\% of reported cases occur in positive HIV individuals (Gbangba-Ngai et al., 2014). The long consultation time is typical in sub-Saharan Africa and is justified by the denial of the underlying disease that requires patients to consult traditionally before resorting to the hospital only tardily (Aoufi et al., 2008; Aoussi et al., 2012). Fever and headache were the major signs in our patients as illustrated in the literature (Gbangba-Ngai et al., 2014). However, it should also be noticed the non-specificity of clinical signs in neuromeningeal Cryptococcus with the possibility of rough or atypical forms (Soumare et al., 2005). Neuromeningeal Cryptococcus is part of lymphocytic meningitis with clear fluid, diagnosed in our series only by CSF analysis with direct examination using Chinese ink (Woldemenuel and Haile, 2001). Examples like CSF culture on Sabouraud medium, the search for Cryptococci antigen could help catch the false negative in direct examination hence contributing to increase the sampling of our series (Katlama and Lubetzki, 1998). The average time to obtain the results is a bit long in our study due to the lack of skilled and equipped technician who must take enough time for the reading but also of the workload with only one laboratory to examine all the levies coming from everywhere. All patients had been treated with fluconazole orally, the only antifungal drug available for the treatment of Neuromeningeal Cryptococcus in Congo. Its combination with $5 \mathrm{FC}$ would be interesting and could improve the prognosis in our patients (Shih et al., 2000). The standard attack treatment of neuromeningeal cryptococcosis is intravenous amphotericin B associated with 5-fluorocytosine for at least 15 days. The effectiveness of this combination is proven despite the rarity of these molecules in our regions (Schwarz et al., 2007; Dromer et al., 2008). 
Only half of our patients were on antiretroviral therapy. This finding corroborates that of several African authors (Dromer, 2001; Schwarz et al., 2007). The reasons for the lack of treatment should be assessed partly in the light of socio-cultural features particular to the populations covered by this study. In Congo, untimely ruptures in antiretroviral drugs justify the absence of treatment in the deceased patients. The lethality of neuromeningeal cryptococcosis is very high in our study and correlated in cases of coma with the Glasgow score lower than 8 as found out elsewhere (Aoufi et al., 2008; Eholié et al., 2000; Kivukuto et al., 2012; Manga et al., 2009; Ouedraogo et al., 2007). The low standard of living of our patients for whom the cost of care is out of reach, the delayed diagnosis, our working conditions characterized by the limitation of the diagnostic and therapeutic means would largely explain this high rate of mortality. It is therefore necessary to prevent this condition for patients who are profoundly immunocompromised by HIV through the early initiation of secondary prophylaxis together with screening and early loading of HIV infection (Charlier et al., 2008; Vibhagool et al., 2003).

\section{Conclusion}

Neuromeningeal cryptococcosis remains a serious opportunistic infection in the Infectious Disease department at Brazzaville University Hospital with a high lethality despite the advent of highly active retroviral tri-therapy. This demonstrates how relevant is prevention which involves the early diagnosis of HIV infection and its management.

\section{Author's Contributions}

Ossibi Ibara Bienven Rolland: To initiate the, work, write the protocol and the article. Coordinated the dataanalysis and contributed to the writing of the manuscript.

Mabiala Babela Jean Robert: Corrdinated the dataanalysis and contributed to the writing of the manduscript.

Attinsounon Cossi Angelo, Atipo Ibara

Ollandzobo Lucie and Sekangue Obili Geril: Corrdinated the mouse work.

Gouesse Grace and Angonga Pabota Ella: To contributed to the collection of data.

Boumandouki Paul Jean Claude and Puruhence

Marie Francke: To correct the article.

Obengui: Organized the study.

\section{Conflit of Interest}

The authors repsit no conflict of interest in relation to this study.

\section{References}

Dromer, F., S. Mathoulin-Pelissier, A. Fontanet, O. Ronin and B. Dupont et al., 2004. Epidemiology of HIVAssociated cryptococcosis in France (1985-2001): Comparison of the pre-and post-HAART eras. AIDS, 18: 555-622.

Aberg, J.A., L.M. Mundy and W.A. Powderly, 1999. Pulmonary cryptococcosis in patients without HIV infection. Chest, 115: 734-740.

DOI: $10.1378 /$ chest.115.3.734

Aoufi, S., A. Agoumi and M. Seqat, 2008. La cryptococcose neuroméningée chez le sujet immunodéprimé au CHU de Rabat(Maroc). Ann. Biol. Clin., 66: 79-81.

Eholié, S.P., D. Adou-Brynh and K. Domoua, 2000. Méningites lymphocytaires non virale de l'adulte à Abidjan (Côte d'Ivoire). Bull. Soc. Pathol. Exot., $93: 50-54$.

Aoussi, E.F., E. Ehui and J.P. Dembélé, 2012. Cryptococcose neuro-méningée et VIH l'ère des antirétroviraux en Côte d'Ivoire. Med. Mal., 33: 1-6.

Sow, P.S., B.M. Diop, Y. Dieng, N.M. Dia and M. Seydi et al., 1998. Cryptococcose neuro-méningée au cours de l'infection à VIH à Dakar. Med. Mal. Infect., 28: 511-515. DOI: $10.1016 / \mathrm{S} 0399-077 \mathrm{X}(98) 80021-8$

Millogo, A., G. Ki-Zerbo, J.B. Andonaba, A. Sawadogo and A. Yameogo et al., 2004. La cryptococcose neuro-méningée au cours de l'infection par le VIH au Centre Hospitalier de Bobo-Dioulasso (Burkina Faso). Bull. Soc. Pathol. Exot., 97: 119-121.

Kivukuto, J.M., S. Mashupe, M.D. Bihehe, T.M. Kashosi, 2012. La cryptococcose neuromeningée chez les patients VIH positifs dans le sud Kivu, République Démocratique du Congo: Pathologie de mauvais pronostic. RevMéd Gd Lacs, 2: 133-151.

Gbangba-Ngai, E., V. Fikouma, C.D. Mossoro-Kpinde, G. Tekpa and J.O. Ouavene et al., 2014. La cryptococcose neuroméningé au cours de l'infection à VIH à Bangui à l'ère du traitement antirétroviral. Bull. Soc. Pathol. Exot., 107: 106-109.

DOI: $10.1007 / \mathrm{s} 13149-014-0337-\mathrm{x}$

Soumare, M., M. Seydi, C.T. Ndour and B.M. Diop, 2005. Aspects actuels de la cryptococcose neuroméningée à Dakar. Méd. Trop., 65: 559-562.

Woldemenuel, Y. and T. Haile, 2001. Cryptococcosis in patients from TikurAnbessa hospital, Addis Ababa, Ethiopia. Ethiop Med. J., 39: 185-192.

Katlama, C. and C. Lubetzki, 1998. Atteintes neurologiques. In: SIDA, Edition 1998.

Shih, C., Y. Chen, S. Chang, K. Luh and W. Hsieh, 2000. Cryptococcal meningitis in non-HIV-infected patients. Q J. Med., 93: 245-51.

DOI: $10.1093 /$ qjmed/93.4.245 
Dromer, F., 2001. Cryptococcose. Rev. Prat, 51: 738-41.

Schwarz, P., J. Guilhem, F. Dromer, O. Lortholary and E. Dannaoui, 2007. Combinaison of amphotericin B with Flucytosine-resistant isolates of Cryptococcus neoformans. Antimicrob Agents Chemother, 51: 383-385.

Dromer, F., C. Bernede-Bauduin, D. Guillemot and O. Lortholary, 2008. Major role for amphotericin Bflucytosine combination in severe cryptococcosis. PLoS One. DOI : 10.1371/journal.pone.0002870

Manga, N.M., S.A. Diop, C.T. Ndour, N.M. Diaa and A. Mendya et al., 2009. Dépistage tardif de l'infection à VIH à la clinique des maladies infectieuses de Fann, Dakar: Circonstances de diagnostic, itinéraire thérapeutique des patients et facteurs déterminants. Méd. Maladies Infectieuses, 39: 95-100.

DOI: 10.1016/j.medmal.2008.09.021

Ouedraogo, S.M., M. Ouedraogo and N.S. Dagnan, 2007. Adom AH Infection opportunistes au cours du Sida au CHU de Treichville. Mali Med., 22: 26-8.
Charlier, C., F. Dromer, C. Lévêque, L. Chartier and Y.S. Cordoliani et al., 2008. Cryptococcal neuroradiological lesions correlate with severity during cryptococcal meningoencephalitis in HIVpositive patients in the HAART era. PLoS One, 3: e1950- e1950. DOI: 10.1371/journal.pone.0001950

Vibhagool, A., S. Sungkanuparph, P. Mootsikapun, P. Chetchotisakd and T. Somsit et al., 2003. Discontinuation of secondary prophylaxis for cryptococcal meningitis in human immunodeficiency virus-infected patients treated with highly active antiretroviral therapy: A prospective, multicenter, randomized study. Clin. Infect. Dis., 36: 1329-1331. DOI : 10.1086/374849

Abbreviation: AIDS: Acquired Immodeficiency Syndrome, CHU: Brazzaville University Hospital, NMC: Neuromeningeal Cryptococcosis, CSF: Staining with Chinese ink, HIV: Human Immunodeficiency Virus, LCR: Cerebrospinal fluid, WHO: World Health Organization 